\title{
Projeto de um jornal impresso com foco na experiência do usuário
}

INICIAÇÃO CIENTÍFICA

\author{
Design of a newspaper printed with \\ focus on user experience
}

Bruna Carvalho das Neves

ttp://lattes.cnpq.br/1403889132761665

\section{Resumo}

O presente artigo propõe-se a fazer um recorte da etapa prática de um trabalho de conclusão de curso. A pesquisa como um todo visa propor a elaboração de um modelo conceitual de jornal impresso com foco na experiência do usuário, na qualse utilizou uma metodologia de projeto aplicada para o desenvolvimento de produtos digitais. Através de modificações estruturais e de navegação no jornal, o projeto procura manter e atrair o público para o consumo da mídia impressa. Para atingir tal objetivo realizou-se o projeto de redesign do caderno Notícias do jornal Zero Hora com base em procedimentos metodológicos da área do design digital.

\section{Palavras-chave}

Design gráfico. Jornal. Experiência do usuário. Convergência. Zero Hora.

\section{Abstract}

This article proposes to make a clipping of the step practice of a work of completion. The research seeks to propose the establishment of a conceptual model of a printed newspaper with a focus on the experience of the user, according to a design methodology applied for the development of digital products. Through structural modifications and navigation in the newspaper, the project seeks to keep and attract the public to the consumption of printed media.

\section{Keywords}

Graphic design. Newspaper. User experience. Convergence. Zero Hora.

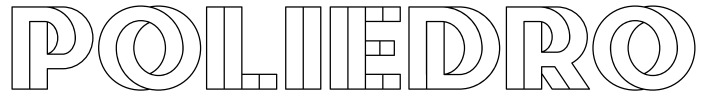




\section{Introdução}

O jornal impresso, uma das mídias de massa mais antigas da história, surgiu da necessidade de comunicação e discussão sobre a sociedade e o Estado (MELO, 2005).

Os avanços tecnológicos proporcionados pela industrialização favoreceram a circulação da mídia impressa, atingindo maior número de leitores. Todavia, segundo Sant'anna (2008), o mercado da informação tornou-se cada vez mais competitivo à medida que outras mídias passaram a dedicar-se às notícias; recentemente a internet passou a "bombardear" os internautas que passam cada vez mais tempo conectados à rede, consumindo notícias praticamente em tempo real.

Sant'anna (2008) acredita que o jornal deveria preocupar-se em oferecer aos leitores conteúdos com análise de qualidade, sem que sejam afetados pela compulsão de apenas transmitir notícias, deixando estas para as mídias ágeis, como a internet. Para Jenkins (2009), essas mudanças evidentes no mercado da informação acontecem devido à convergência midiática, quando as mídias antigas interagem com as emergentes e os conteúdos fluem através de diferentes suportes midiáticos, alterando a forma de consumo da informação. Segundo Galan (2013), ao invés de declínio, o jornal encontra-se num "debate de sentidos", em um momento de reposicionamento dos sistemas de comunicação. Além disso, o autor aponta as influências do meio digital sobre o meio impresso, no qual códigos de um determinado meio se expandem para fora do seu contexto de origem e tornam-se padrões culturais.

Desta forma, este trabalho se propôs a investigar os aspectos de navegação e usabilidade das mídias digitais que puderam auxiliar na concepção de um modelo conceitual de jornal impresso diante do atual cenário de convergência midiática. Esta pesquisa, em síntese, propõe o desenvolvimento de um modelo conceitual de jornal impresso com foco na qualidade da experiência do usuário através do redesign do caderno Notícias do jornal Zero Hora, com objetivo de manter e atrair potenciais leitores à mídia impressa. Através dessa premissa, utilizou-se uma metodologia do design digital, na qual o principal interesse foi o de adequar a usabilidade do meio ao potencial usuário. Com essa fina- 
lidade, empregou-se a metodologia proposta por Jesse James Garret (2002) dividida em cinco planos de experiência, a qual abrange desde a concepção até a maturidade de projetos orientados à informação.

A metodologia utilizada para o desenvolvimento da pesquisa compreendeu a pesquisa bibliográfica. A etapa prática abrangeu desde a definição do conceito do projeto até sua execução final prevista de acordo com os processos metodológicos de Jesse James Garrett (2002), da área do design digital.

\section{A experiência do usuário e o redesign do caderno de notícias da Zero Hora}

Garrett (2002) acredita que todo projeto de design destinado à experiência do usuário requer que determinadas etapas sejam seguidas, independentemente do projeto estar alocado na área digital. A utilização da estrutura de Garrett (2002) tornou-se pertinente ao projeto devido ao fato de que cada camada do plano de experiência é analisada separadamente, uma vez que o redesign do caderno Notícias do jornal Zero Hora não foi aplicado a todos os planos.

Os planos foram divididos em 5 (cinco) e construídos de baixo pra cima, do mais abstrato para o mais concreto.

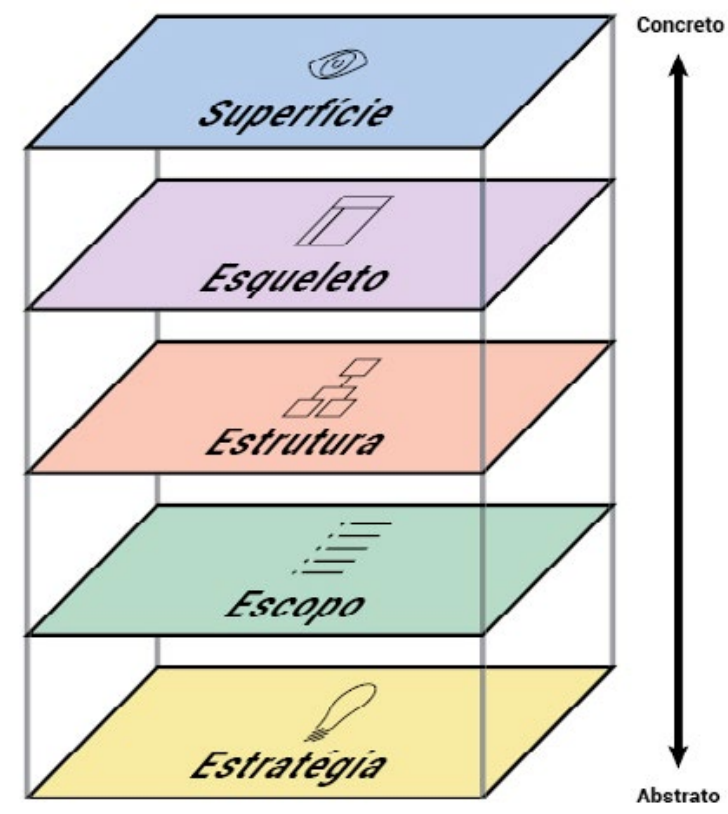

Figura 1 - Planos da experiência. Fonte: GARRETT (2002), tradução da autora.

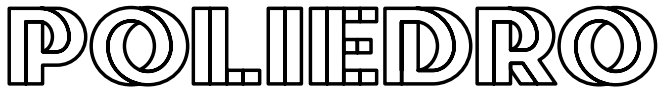




\section{Plano de estratégia}

O Plano de Estratégia consistiu em definir os principais conceitos e objetivos do projeto, assim como conhecer quem são os usuários, as suas necessidades e expectativas (GARRETT, 2002).

Ao se tratar de um projeto voltado para uma mídia de comunicação de massa, fez-se necessário conhecer o cenário do mercado da informação, a maneira que as pessoas consomem as mídias e identificar quem é o público do jornal Zero Hora.

Dados da Pesquisa Brasileira de Mídia de 2015 apontam o consumo e combinação diversificada de mídias de comunicação. De acordo com o Mídia Kit da Zero Hora de 2015, 21\% dos entrevistados consomem a mídia impressa uma vez por semana e $7 \%$ consomem diariamente, dados que permaneceram estáveis. Segundo a pesquisa, a principal motivação para o consumo da mídia é a busca de informação e notícias, o que corresponde a $84 \%$ dos leitores, justificando a escolha do redesign do caderno Notícias.

Uma pesquisa qualitativa descrita por Sant'anna (2008) procurou investigar a percepção dos públicos de classe $A$ e $B$ em relação aos meios de comunicação. Em suma, os participantes da pesquisa relataram a necessidade de mudanças na linguagem dos jornais, no formato, tamanho, papel (considerado "sujo") e tipografia, sugerindo que fossem utilizados recursos que facilitassem a compreensão e a contextualização da notícia de uma forma mais descontraída, sem perder a credibilidade. Portanto, percebeu-se a necessidade de rever algumas definições dos jornais impressos para expandir a experiência do usuário na mídia analógica.

Considerando a tendência de preferência e migração dos leitores para o suporte digital e interativo já identificado por Galan (2013), e ao mesmo tempo a desconfiança dos leitores com respeito à informação obtida no ambiente online, o redesign do caderno Notícias de Zero Hora visou unir conceitos do design digital - no que tange ao hipertexto e a navegação no ambiente web - a conceitos do design gráfico - voltado para a enunciação jornalística em que atuam influências da convergência midiática - com o objetivo de manter, mas principalmente atrair leitores ao consumo de notícias e informações no suporte impresso que proporcione uma experiência de leitura dinâmica e objetiva. 


\section{Plano de escopo}

No Plano de Escopo são trazidas as necessidades e os objetivos do produto da etapa anterior, transformando-os em requisitos específicos de conteúdo e funcionalidade que serão oferecidos ao usuário (GARRETT, 2002). Porém, visto que o foco do projeto não se atém à coleta e edição das notícias, foram utilizados conteúdos referentes às editorias de notícias do jornal Zero Hora dos dias 13/02/2016 e 25/02/2016.

No Plano de Escopo de um jornal impresso, pode-se considerar as decisões tomadas em um projeto editorial para atender às demandas dos leitores. Como visto anteriormente, o jornal Zero Hora está dividido atualmente em quatro editorias/cadernos: Notícias, Esporte, Sua Vida e Segundo Caderno.

Visto que o projeto de redesign abrange apenas o caderno Notícias, tornou-se importante conhecer suas divisões e quantidade de matérias abordadas em cada seção. 0 caderno está dividido em 5 (cinco) seções fixas: Especial, Política, Economia, Mundo e Polícia, respectivamente. No projeto de redesign foi acrescentada uma seção relacionada a assuntos rurais, devido ao contexto socioeconômico do estado de atuação do jornal e a sua recorrência entre as seções Economia e Mundo, sendo destinado um espaço para colunistas que tratam sobre assuntos da área rural, ocupando apenas uma página com variedade de informações da área. Porém essa será uma seção com rotulagem flexível, passível de mudança de assunto de acordo com as necessidades pontuais do jornal.

\section{Plano de estrutura}

Após definidos os requisitos, deve-se descrever como eles integram a estrutura conceitual do projeto. Organizar o conteúdo aliado à experiência do usuário é uma questão de arquitetura de informação, que se preocupa com a organização, ordenação, agrupamento e apresentação do conteúdo, tornando-se importante, nessa parte do projeto, definir padrões e sequências lógicas em que as opções serão apresentadas ao usuário (GARRETT, 2002).

Outro conceito também abordado nesse plano foi o design de interação, cujo objetivo consistiu em projetar através da perspectiva do usuário trazendo aspectos da usabilidade para o processo de design (PRE- 
ECE; ROGERS e SHARP, 2005). Ao propor um modelo conceitual para o caderno Notícias, foi pensada primeiramente a relação do usuário com o produto e então analisada como poderia ser aprimorada a experiência de leitura tendo como referência a forma de navegação e interação no ambiente digital. Esse processo resultou em um modelo de jornal que difere dos padrões formais estabelecidos para a mídia.

No Plano de Estrutura foram analisados os planos anteriores como forma de concretizar as ideias que iriam contribuir e determinar como seria a experiência do usuário no produto, desenvolvendo uma estrutura conceitual (GARRETT, 2002). Na concepção de projetos de sites, nessa etapa foi construído o mapa do site, que permitiu mostrar a estrutura da página e suas relações de forma visual. Segundo Garrett (2002), essa é considerada a melhor ferramenta de documentação para a arquitetura de informação.

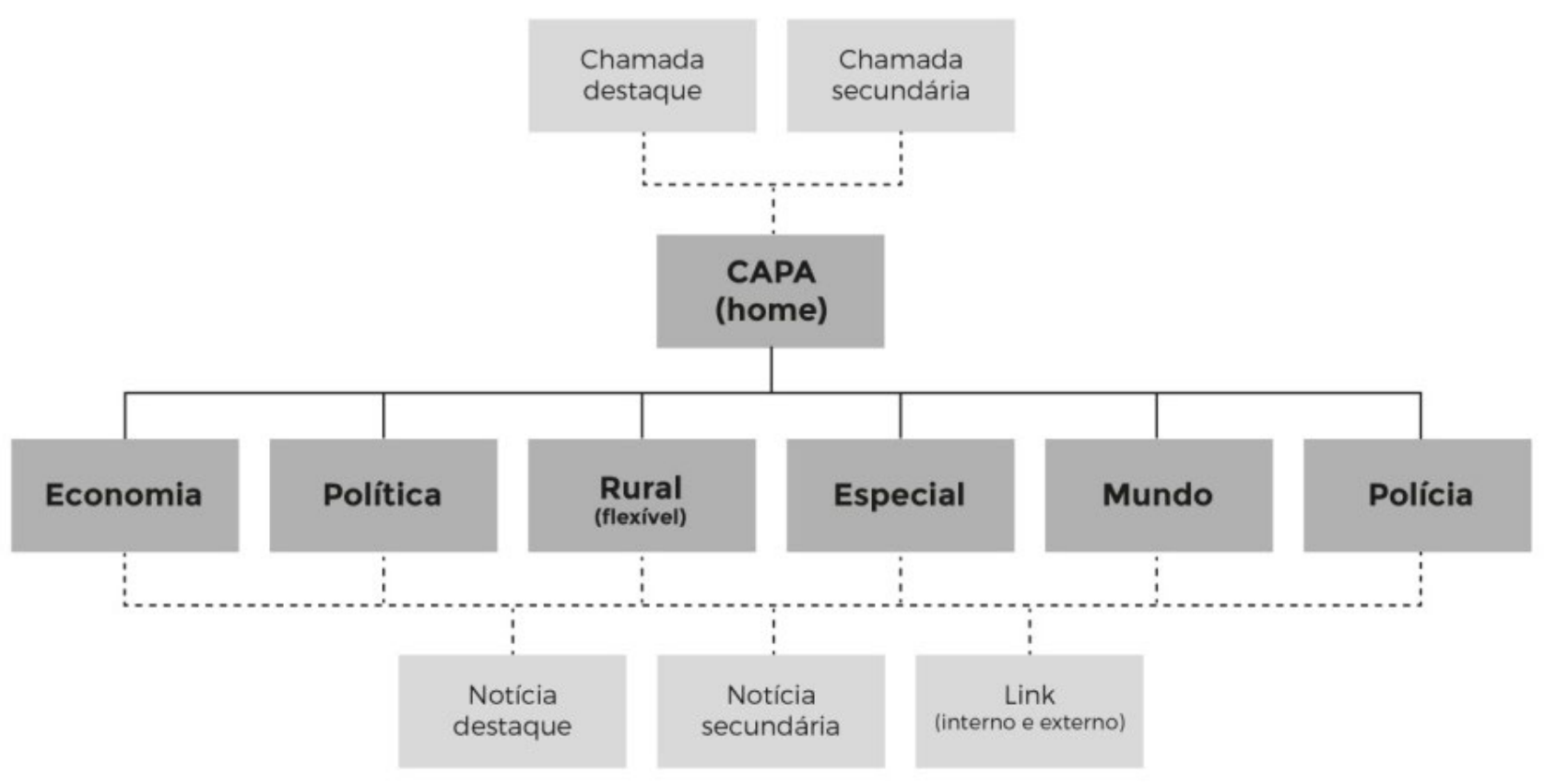

Figura 2 - Estrutura do caderno. Fonte: Elaborado pela autora

Através da estrutura do caderno (Figura 2), a capa da publicação funcionou como a home, página principal de um site, na qual são apresentadas chamadas para conteúdos internos e menu de acesso rápido às categorias disponíveis através das abas de conteúdo. Dentro de cada 
aba, as informações ficaram divididas entre notícias de destaque (de maior importância e conteúdo), notícias secundárias e conteúdo complementar através de links que redirecionam o leitor para o site, além de chamadas para outras abas.

Para atingir o objetivo de propor ao usuário uma experiência de navegação próxima ao meio digital, foi preciso pensar em uma forma de referenciar o modo de navegação hipertextual no suporte de papel, em que as opções de leitura fossem apresentadas ao leitor conforme os menus/links disponíveis nas mídias digitais, com redirecionamento direito ao assunto escolhido.

Como forma de aplicar esses conceitos, propos-se um formato de jornal impresso verticalizado, com dobras originando abas que fazem referência ao hipertexto, proporcionando uma navegação não-linear, em que o leitor desloca-se diretamente ao assunto de interesse. Essa não-linearidade iguala o grau de importância das editorias e facilita o acesso intuitivo do usuário ao conteúdo, cabendo ao leitor o poder da escolha de forma mais ágil, sem a necessidade de percorrer o caderno inteiro para isso. Além disso, através da verticalidade do formato impresso em uma folha única, foi possível oferecer ao usuário o princípio da segurança, uma das metas do design de interação que consiste em protegê-lo de situações indesejadas como a mudança de ordem acidental das páginas, desorganizando a publicação.

Diferente dos padrões convencionais de jornal impresso como os formatos mais utilizados, o tablóide - que mede aproximadamente 35,5 x 25,5 30,5cm - e o standard - que mede aproximadamente 56 x 43,2 cm (ZAPPATERRA; CALDWELL, 2014), o formato ${ }^{[1]}$ de $29,7 \times 178,5 \mathrm{~cm}$ com dobras permitiu dividir o caderno em diversas seções que puderam ser identificadas através das abas.

A divisão e a organização das abas seguiram dois critérios: O primeiro critério foi estabelecido através das dimensões de cada área, definida pelas dobras do impresso. Devido ao formato sanfonado, as últimas abas possuem maior espaço, sendo destinada a tópicos com maior 
quantidade de conteúdo. O segundo critério adotado foi a aproximação das seções em relação ao caderno original, desde que respeitasse o critério anterior. A escolha da ordem das abas foi de difícil definição, uma vez que a ordem de leitura dos assuntos depende exclusivamente do interesse do leitor. Esta característica apromixou o projeto da linguagem do hiperlink, proporcionando uma forma de leitura não-linear e de estrutura definível pelo próprio usuário.

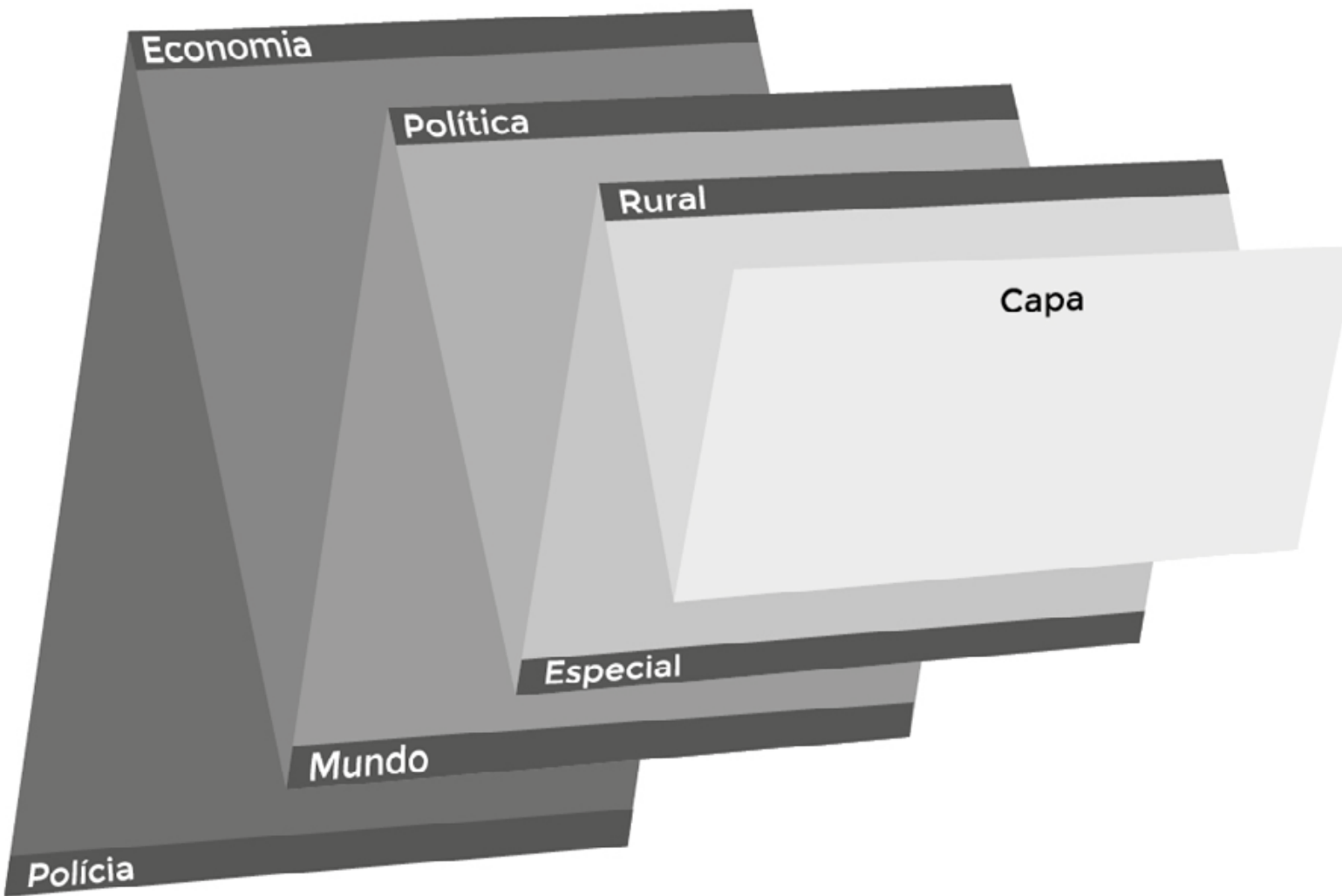

Figura 3 - Divisão das abas. Fonte: Elaborado pela autora

Por se tratar de um projeto conceitual com foco exclusivo nas decisões de design que possam ampliar as experiências de leitura das informações, as áreas comerciais do jornal foram desconsideradas. 


\section{Plano de esqueleto}

O plano de esqueleto define a forma como a estrutura irá funcionar, bem como a sua navegação, a partir da organização do conteúdo e das definições de funcionalidade em uma forma mais concreta de apresentação (GARRETT, 2002). Essa parte do projeto unifica o design de interface e o design de navegação, nominando então o design da informação que consiste na apresentação das informações de forma eficaz (GARRET, 2002). Segundo o autor, quando o design de informação estabelece uma comunicação efetiva com o usuário, permite que ele produza a habilidade de "fazer coisas", de permitir ao usuário o contato com as funcionalidades definidas anteriormente, resultando no design de interface.

Embora a estrutura do jornal proponha um modelo diferente das demais mídias impressas, a modalidade de navegação intuitiva e objetiva pode ser realizada através elementos que redirecionam o leitor à seção escolhida.

Segundo Garrett (2002), existem diversas modalidades de navegação exploradas pelos sites que podem atuar de forma concomitante. De acordo com o autor, o design de navegação refere-se aos elementos disponíveis ao usuário que permitem sua movimentação através da arquitetura de informação, e que devem realizar simultaneamente três objetivos.

O primeiro objetivo consiste em disponibilizar ao usuário um meio de navegação de um ponto para outro. A disponibilização do conteúdo ao usuário, realizada por meio das abas, podem ser visualizadas em sua totalidade com o caderno fechado. Essa modalidade de navegação caracteriza a navegação global, que fornece ao usuário amplo acesso das opções disponíveis, mesmo que essa navegação não esteja presente em todas as páginas do site, reunindo um conjunto de pontos de acesso (GARRETT, 2002).

O segundo objetivo consiste em comunicar ao usuário a lógica dos links que estão disponíveis a ele. No formato sanfonado proposto para o projeto, o processo de abertura das seções acaba impossibilitando a disponibilidade simultânea de todas as abas oferecidas ao usuário, devido à sobreposição de algumas abas com o desdobramento da página. Para suprir a necessidade de informar ao usuário todas as opções disponíveis a ele, mesmo dentro de cada seção, foram utilizados links 
que informam a direção das abas mais próximas da seção em que ele se encontra. Com isso, o usuário poderá orientar-se da localização das demais opções, sem que precise fechar o caderno para visualizar o todo. Essa modalidade de navegação caracteriza a navegação local, na qual o usuário é informado sobre os acessos disponíveis por aproximação da arquitetura de informação (GARRETT, 2002).

$O$ terceiro objetivo deve servir como ferramenta de orientação, informando o conteúdo que está sendo visualizado (GARRETT, 2002). Essa função é definida pelo design de informação como wayfinding, que auxilia o usuário a entender o local em que ele está e quais suas possibilidades de navegação (GARRETT, 2002). O termo descreve como os indivíduos orientam-se dentro de um novo ambiente e como utilizam seu processo cognitivo para determinar um caminho (O'GRADY, 2008).

\section{TítULO ABA}

Figura 4 - Abas. Fonte: Elaborado pela autora

As abas que funcionam como elemento de navegação, também possuem função de orientar o usuário sobre a seção em que se encontra, devido à sua diferenciação gráfica prevista com o restante da página. A aba externa proporciona a navegação global no impresso, já a aba interna, a navegação local. Através dessa modalidade de navegação hipertextual, torna-se desnecessária a paginação no impresso, uma vez que se desconhece o caminho que o leitor irá percorrer.

Para Garrett (2002), nesse plano são construídos os wireframes, responsáveis por transpor as decisões estruturais do projeto em um documento que sirva de referência para o design visual no Plano de Superfície. Essa estrutura de organização espacial dos wireframes assemelha-se à função exercida pelo sistema de grid enquanto ferramenta utilizada para guiar a distribuição de elementos em um formato (SAMARA, 2011), geralmente utilizado na estruturação de páginas impressas. Segundo Garrett (2002), as definições de layout possuem um grau de importância elevado 
para o projeto, pois é onde o design de informação, de interface e de navegação se unem para formar uma estrutura unificada, cabendo ao wireframe representar os componentes da página e a forma em que elas coexistem, sendo responsável pela hierarquia e organização dos elementos.

O formato sanfonado proposto, para que fosse possível uma experiência de navegação semelhante ao meio digital, implicou algumas peculiaridades que se refletem diretamente no grid do projeto.

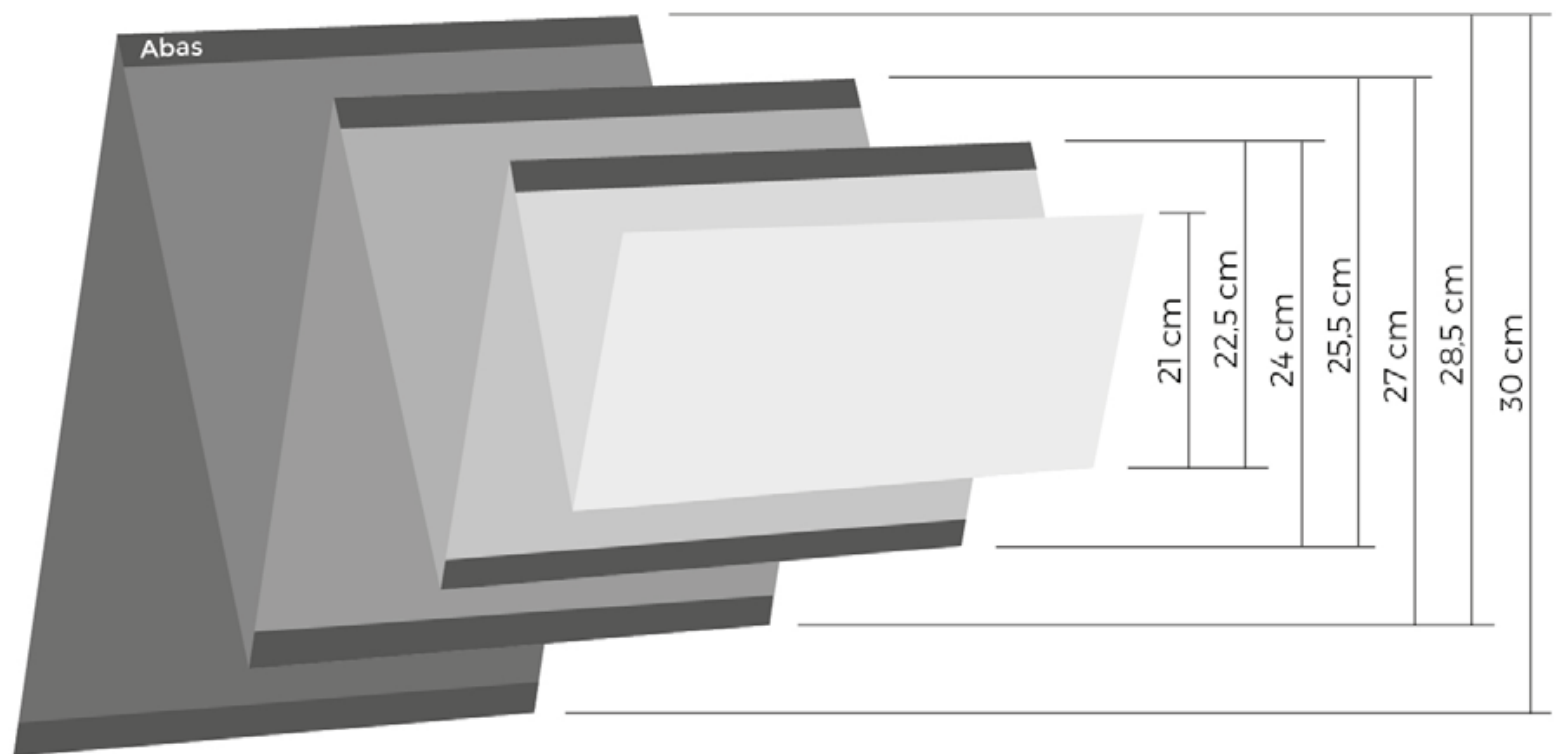

Figura 5 - Dimensões. Fonte: Elaborado pela autora

Cada conjunto de dobras, identificadas pelas abas, correspondeu às divisões existentes no caderno de Notícias, como notícia Especial, Política, Economia, Mundo, Polícia, e também a aba Rural, acrescentada pelo projeto de redesign. $\mathrm{O}$ jornal teve como base o formato A4, no sentido horizontal para que pudesse se adaptar ao projeto do jornal Zero Hora, em que cada página possui a largura aproximada de $29,7 \mathrm{~cm}$, sendo mantida essa medida. Já a altura de cada seção corresponde aos 21 $\mathrm{cm}$ da capa, acrescido de $1,5 \mathrm{~cm}$ por cada aba que a antecedia totalizando um comprimento de $178,5 \mathrm{~cm}$. 
Porém, por mais que se tente manter o sistema de grid do caderno de Notícias, devido à variação de comprimento de cada seção foram necessárias adaptações no grid para acomodar as informações. A maior preocupação na adaptação foi chegar a um resultado que as larguras das colunas fossem compatíveis com as utilizadas no projeto gráfico de Zero Hora.

Para conseguir obter resultados próximos ao original e reproduzir a organização do layout, foram estabelecidos dois grids, um de 12 colunas e outro de 15 colunas.

Grid 12 colunas

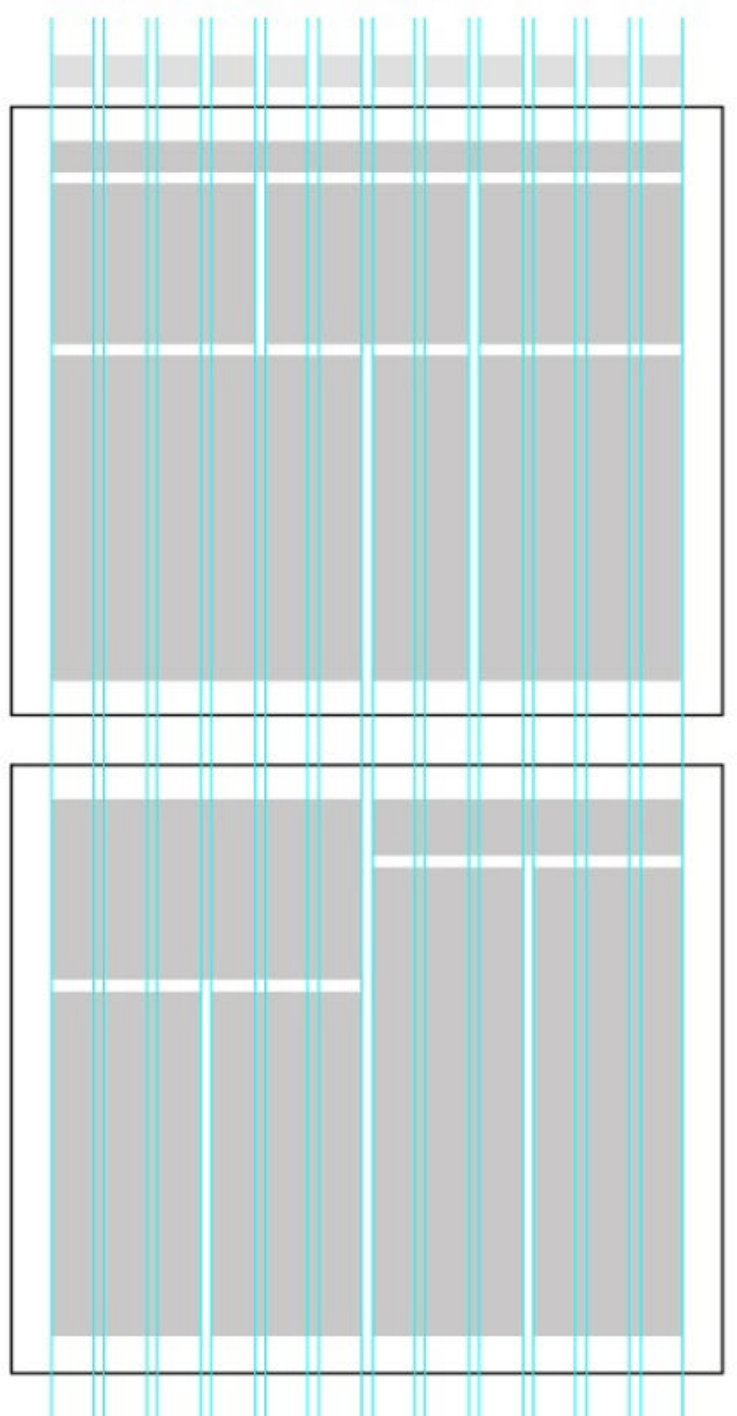

Grid 15 colunas
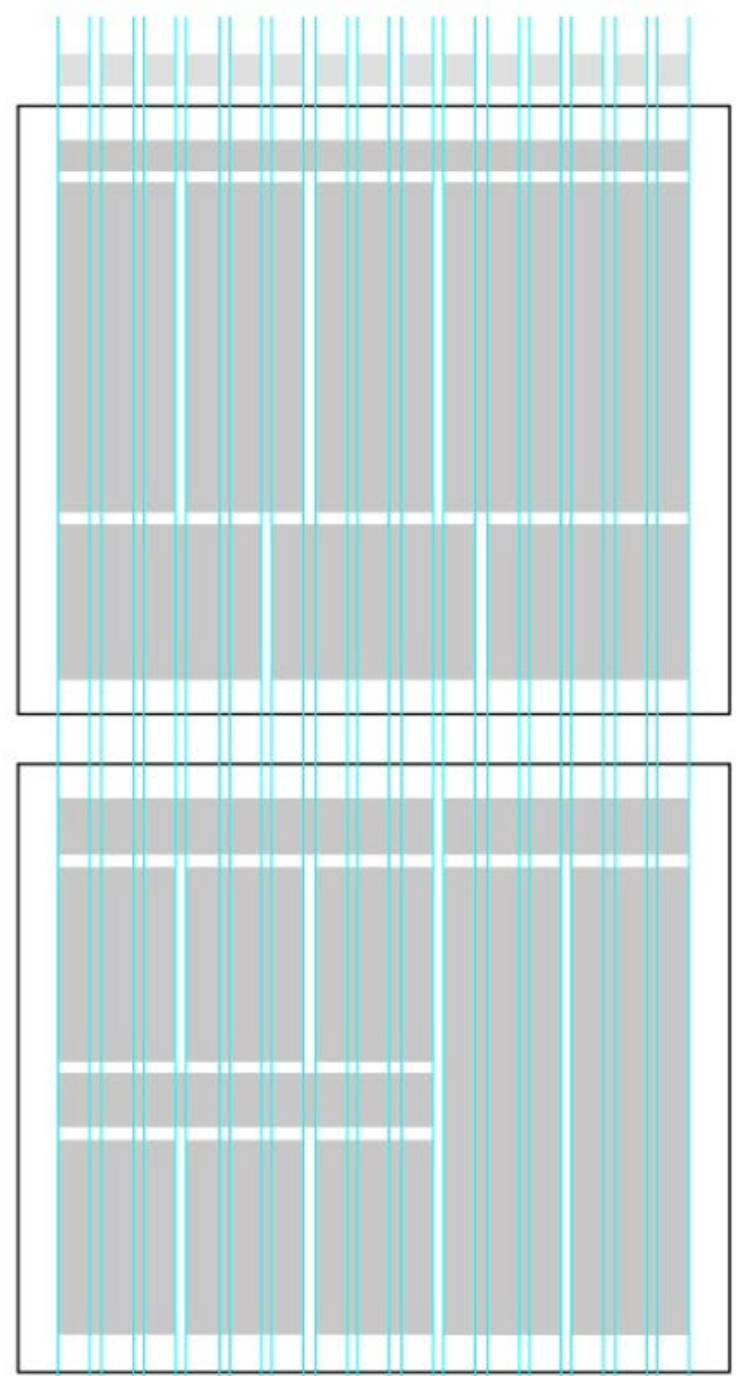

Figura 6 - Grid. Fonte: Elaborado pela autora 
Segundo Samara (2011), os grids híbridos surgem de acordo com o grau de complexidade da publicação, possibilitando utilizar um modelo para cada situação. $O$ grid de 12 colunas possibilita a utilização de parágrafos mais largos e também a combinação par do número de colunas. O grid de 15 colunas possibilita a utilização de parágrafos mais estreitos e composições ímpares de colunas. As margens laterais consistem em 2 $\mathrm{cm}$ e as margens superiores e inferiores $1,5 \mathrm{~cm}$.

\section{Plano de superfície}

O Plano de Superfície consiste nos aspectos do produto mais perceptíveis aos usuários, responsável pela facilidade de uso, de aprendizado, de memorização e agradabilidade do produto devido ao cumprimento de todas as metas dos planos anteriores (GARRETT, 2002). Neste plano, foram estudadas as decisões visuais acerca do projeto gráfico do jornal Zero Hora, com intuito de mantê-las ou, em alguns casos, adaptá-las a fim de preservar a identidade visual do projeto original, salientando que o projeto conceitual proposto encaixa-se nas definições gráficas já estabelecidas.

De acordo com Garrett (2002), é a última etapa do projeto a qual determina como a experiência do usuário manifestará os sentidos das pessoas, sendo eles visão, audição, tato, olfato e/ou paladar. No caso dos jornais impressos, podemos destacar o tato, a audição e a visão.

0 tato estabelece a experiência de toque de um produto físico podendo implicar considerações puramente sensoriais quanto à forma do dispositivo, as texturas utilizadas e a escolha dos materiais que comunicam alguma coisa ao usuário (GARRETT, 2002). Em relação à forma, 0 que difere o projeto proposto do convencional é o formato verticalizado necessário para que sejam feitas dobras que originam as abas de conteúdo, e a folha única do impresso que facilita o manuseio, evitando que as folhas se soltem e desorganize as páginas. Além disso, levando em consideração a percepção do usuário em relação ao aspecto "sujo" do jornal, mencionado no Plano de Estratégia, optou-se pela escolha do papel sulfite branco na gramatura $110 \mathrm{~g} / \mathrm{m}^{2}$, para que a estrutura seja mais consistente e sustente o conjunto de dobras, facilitando o manuseio das abas e reduzindo o risco de rompimento do papel. 
A audição desempenha um papel na experiência do usuário tanto para avisá-lo sobre algo, como o exemplo dos carros que emitem sons para sinalizar que a porta não está travada ou que os faróis estão acesos, quanto para transmitir um senso de personalidade como sons característicos de certos produtos ou serviços (GARRETT, 2002). Portanto, uma das grandes diferenças da experiência de leitura de jornais no âmbito digital e analógico, são os sentidos explorados de acordo com o suporte em questão. Na mídia online, geralmente os sons são reproduzidos para informar o usuário sobre uma ação ou informação pontual, servindo como sinalização. Na mídia impressa, o som emitido pelo manuseio do papel transmite uma característica da mídia quanto ao seu suporte físico.

A visão permite aos designers de experiência do usuário um grau maior de sofisticação, o design visual. Essa etapa não somente se detém ao que é esteticamente agradável, mas principalmente em fazer com que o design visual expresse como um todo o processo de construção da experiência do usuário, como uma questão de estratégia (GARRETT, 2002). Nesse momento, os conceitos do design gráfico zelam por aspectos formais dos jornais, como a tipografia, a cor e elementos gráficos.

Portanto, como o redesign do projeto possuiu o foco nos planos de Estrutura e de Esqueleto, dos demais não sofreram alterações.

\section{Conclusão}

Acredita-se ter atingido os objetivos inicialmente traçados para a pesquisa. Através dos estudos e da metodologia aplicada, chegou-se ao resultado de um jornal impresso que proporciona ao leitor maior liberdade de escolha e objetividade na leitura.

Pôde-se concluir que atualmente o jornal encontra-se na Fase Convergencial. Por esta pode-se entender não a internet em si como agente transformador, mas sim a capacidade de expandir seus conceitos para fora do contexto inserido em velocidade e proporção imensurável. A forma como o indivíduo interage no meio online vai além da sua interação no dispositivo digital, e acaba se refletindo nos padrões culturais da sociedade.

Através dessa pesquisa, pôde-se observar que a tendência à "hipertextualização" (LÉVY, 1993) ganhou mais força com o dinamismo da internet, onde o tempo de ação e reação tornou-se cada vez menor. É esse 
estímulo dinâmico e objetivo que este trabalho de conclusão de curso buscou trazer à mídia, que é considerada por muitos como ultrapassada.

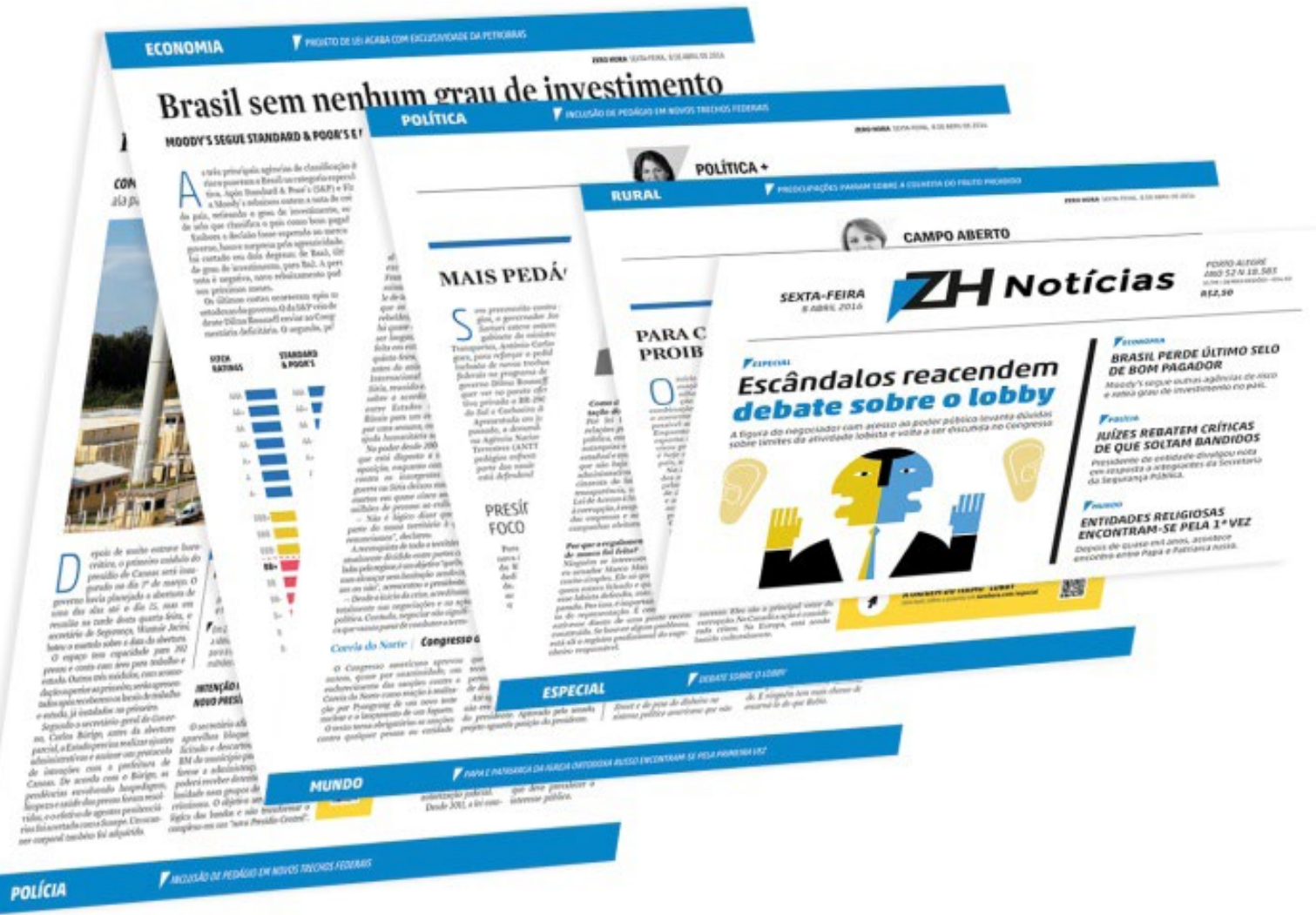

Figura 7 - Resultado final. Fonte: Elaborado pela autora

Através de estudos e de uma metodologia do âmbito digital, que considera a experiência do usuário no desenvolvimento do projeto, pôde-se aliar esses conceitos aos estudos relativos ao design editorial a fim de desenvolver um modelo conceitual de jornal que exprimisse os conceitos de navegação e interação da mídia digital. Porém, em alguns momentos foram encontradas dificuldades em relacionar as decisões de um projeto gráfico jornalístico com o desenvolvimento de mídias digitais conforme a metodologia de Garrett (2002) por conter poucas referências de projetos gráficos com a utilização de metodologias mais flexíveis da área digital. Contudo, o procedimento metodológico mos- 
trou-se eficiente e aplicável para a proposta de redesign, visto que as principais alterações do projeto referiram-se aos Planos de Estrutura e de Esqueleto, que consiste na arquitetura de informação e na navegação do jornal, foco principal dessa pesquisa.

A aplicação de metodologias do design digital para um projeto da área gráfica pode enriquecer os projetos da área do design gráfico, estimulando-o a projetar fora dos padrões convencionais. Considero que essas questões podem servir de base para futuras pesquisas.

\section{Referências}

GALAN, D. V. Para além dos links: Diálogo entre o meio digital e o impresso. 2013. 116p. Mestrado. Universidade de São Paulo.

\section{GARRET. J. J. The Elements of User Experience.}

San Francisco: Peachpit Press, 2002.

JENKINS, Henry. Cultura da convergência.

2. ed. São Paulo: Aleph, 2009.

LÉVY, Pierre. As tecnologias da inteligência.

São Paulo: Editora 34, 1993.

Cibercultura. Traduzido por Carlos

Irineu da Costa. São Paulo: Editora 34, 1999.

MELO, P. B. de. Um passeio pela História da Imprensa:

0 espaço público dos grunhidos ao ciberespaço.

Comunicação \& Informação / Universidade Federal de Goiás, Faculdade de Comunicação e Biblioteconomia. V. 8, n. 1, (jan./ jun. 2005). Goiânia: UFG, Facomb, 2005.

MIDIA KIT ZERO HORA. 2015. Disponível em: <http://feedcomercial. com.br/Arquivos/abe56eda20eb874b6565c67f0f16acc4. pdf>. Acesso em: 03 fev. 2016. 
O'GRADY, J.; O'GRADY, K. The information design handbook. Switzerland: RotoVision. 2008.

PREECE, J; ROGERS, Y; SHARP, H. Design de Interação: Além da interação humano-computador. Porto Alegre: Bookman, 2005.

SAMARA, Timothy. Grid: Construção e

Desconstrução. Cosac Naify, 2007. Guia de design editorial: manual prático para o design de publicações. Porto Alegre: Bookman, 2007.

SANT'ANNA, Lourival. 0 destino do jornal: a Folha de S. Paulo, O Globo e o Estado de S. Paulo na sociedade da informação. Rio de Janeiro: Record, 2008.

SECOM, Secretaria de Comunicação Social. Pesquisa brasileira de mídia 2015: hábitos de consumo de mídia pela população brasileira. Brasília, 2014. 153 p. Disponível em:< http:// www.secom.gov.br/atuacao/pesquisa/lista-de-pesquisasquantitativas-e-qualitativas-de-contratos-atuais/pesquisabrasileira-de-midia-pbm-2015.pdf>. Acesso em: 03 fev. 2016.

ZAPPATERRA, Y; CALDWELL, C. Design editorial: Jornais e revistas/ Mídia impressa e digital. São Paulo: Editora G.Gili, 2014. 